\title{
froven
}

\section{A PERFORMANCE DO CORDEL COMO PRÁTICA DE LEITURA LITERÁRIA}

\author{
Carlos Magno Gomes ${ }^{1}$ \\ Claudia Zilmar da Silva Conceição
}

\begin{abstract}
RESUMO: Este artigo traz uma reflexão sobre o ensino de literatura a partir da leitura e interpretação da cultura oral e do cordel. Para tanto, sugerimos a introdução da cultura popular como parte dos conteúdos significativos que despertam o interesse e a motivação dos leitores em conhecer a diversidade cultural do cordel. Metodologicamente, exploramos conceitos de cultura popular e performance, propostos por Hall e Zumthor. Quanto ao ensino de literatura, exploramos os métodos de leitura interdisciplinar e subjetiva defendidas por Rouxel e Cosson. Como abordagem de intervenção, propomos oficinas de literatura de cordel.
\end{abstract}

PALAVRAS-CHAVE: Leitura, Literatura de cordel, Performance.

\begin{abstract}
This paper presents a reflection on the teaching of literature from the reading and interpretation of oral culura and string. We envisage the introduction of popular culture as part of meaningful content that arouse the interest and motivation of readers know the cultural diversity of the cordel. Methodologically we explore concepts of popular culture and performance , proposed by Hall and Zumthor. As for the teaching of literature, we explore methods of interdisciplinary and subjective reading advocated Rouxel and Cosson. As an intervention measure , we propose Cordel literature workshops.
\end{abstract}

KEYWORDS: Reading, Cordel Literature, Performance.

Este artigo traz resultados de uma pesquisa sobre a prática do ensino de literatura. Nossa proposta partiu de vivências de leituras de cordel nas aulas de língua portuguesa, no ensino médio. O principal enfoque foi desenvolver o gosto pela leitura performática do cordel, explorando suas particularidades orais e estéticas, como a musicalidade e o ritmo de suas trovas. Para tanto, planejamos oficinas práticas, intituladas vivências de literatura de cordel, nas quais convidamos os alunos a entrar em contato com o texto para experimentá-lo a partir de suas práticas de leituras e de seus entendimento de mundo.

\footnotetext{
1 Universidade Federal do Sergipe. E-mail para contato: calmag@bol.com.br.

2 Mestre em Crítica Cultural pela UNEB (2015). Professora da Secretaria do Estado de Educação da Bahia. E-mailpara contato: cauzilmar@gmail.com.
} 
Fizemos uso do termo "vivências", para os fins das discussões realizadas nesta pesquisa, apesar de saber que experiência é um termo correlato. Exploramos a vivência como algo mais pleno, visto que envolveu o sujeito em sua plenitude a partir de sua própria história pessoal, sem deixar de lado as marcas de sua comunidade. Ou seja, na vivência, lidamos com os laços da personalidade e a situação representada na prática experimentada.

Nessa perspectiva, organizamos quatro vivências que se constituíram em nossa escolha para intervenções com os alunos do ensino médio. A saber: a recepção do cordel, a leitura em voz alta, a performance e a formação do leitor crítico. Deixamos claro que todas as atividades foram respaldadas por teorias e planos estrategicamente elaborados a fim de levar em consideração o contexto social do grupo e a subjetividade nas escolhas temáticas. Portanto, pretendíamos expandir a ideia de ensino de literatura tradicional, que restringiu a literatura à história das grandes obras e de autores reconhecidos em livros didáticos e exames de vestibular.

\section{A leitura literária pelos estudos culturais}

A leitura literária tem se tornado cada vez mais rarefeita no âmbito escolar, pois, na aula de literatura, as leituras vão se convertendo em simulacros: apenas resumos, compilações, algumas informações sobre os autores, cronologia literária e alguma teoria sobre gêneros. No ensino fundamental, "tem a função de sustentar a formação do leitor e, no ensino médio, integra esse leitor à cultura literária brasileira, constituindo-se, em alguns currículos, uma disciplina à parte da Língua Portuguesa" (COSSON, 2009, p.20). Entretanto, as leituras do cânone nacional, propostas pela escola, há muito tempo, já não despertam a atenção dos estudantes.

Teresa Colomer (2007), em seu livro "Andar entre livros", explica que os professores têm predileção por textos informativos, por serem fáceis de entender e de controlar ante as sutilezas que são exigidas das leituras literárias. E o que, talvez, seja o mais chocante é que essa crença também é compartilhada pelos pais de diferentes classes sociais, que não veem de forma prática o fato de seus filhos perderem tempo com divagações literárias.

Em tal contexto, quando há o entrelaçamento entre o ensino de língua e literatura, muitas vezes, o professor acaba suprimindo o de literatura por não despertar o interesse dos alunos. Nesse caso, o ensino da leitura e da escrita passa a se configurar de forma técnica, não introduzindo melhora alguma, "é possível afirmar que a restrição escolar da literatura não parece ter sido benéfica para a formação linguística dos alunos” (COLOMER, 2007, p.36).

Contrários ao ensino técnico, ressaltamos a importância do ensino de literatura para além dos mecanismos linguísticos, valorizando sua força cultural e sua fonte de prazer. Nessa direção, defendemos uma prática de ensino performática, que valorize a forma como o aluno recepciona o texto de cordel a partir de suas experiências pessoais. É preciso colocar a leitura como um andaime para uma efetiva reflexão social que leve o educando à formação e ao exercício da cidadania. Trata-se, então, de "ver a obra em uma cultura ativa não só no seio da literatura, mas na relação literatura/realidade" (ROUXEL, 2013, p.159), pois a forma como a literatura está sendo trabalhada na escola apenas fortalece a resistência do alunado perante o texto literário.

Por um prisma que valoriza a cultura local, podemos levar em conta aspectos da proposta de Stuart Hall, que propõe um modelo de leitura composto de três posições hipotéticas de decodi- 
ficação de leitura: a primeira seria a preferencial, por ter uma forma determinante, a mensagem é decodificada segundo os critérios de quem detém o poder: "leia-me dessa forma"; a segunda versão é negociada quando a mensagem entra em negociação com as condições de adaptação e oposição às "condições locais"; finalmente, a leitura de oposição em que as pessoas entendem a mensagem mas contestam. Esse modelo demonstra, principalmente, que o processo de decodificação não é homogêneo, e que se pode ler de formas diferentes (HALL, 2003, p.357).

Nesta prática, valorizamos essa terceira fase, a fase de diálogo e decodificação em conjunto, marcada pelo prazer da leitura, pois "quando não há prazer - ou ele cessa - o texto muda de natureza” (ZUMTHOR, 2000, p.35). Para nossas oficinas, ressaltamos a leitura subjetiva e prazerosa. Essa prática está contextualizada, já que o relacionamento do texto lido com o espaço de recepção, "implica a busca de uma significação senão universal ao menos consensual na comunidade cultural” (ROUXEL, 2013, p.152). É sob esta óptica que a leitura subjetiva nos remete à nossa memória pessoal, que faz parte de uma leitura privada; mas também nos convida a pensar nos sentidos coletivos, posto que interpretar é a cisão entre "direitos do texto" e "direitos do leitor", portanto, passíveis de uma carga de subjetividade.

Por uma prática de leitura libertária, ressaltamos uma prática performática para além das interpretações dos professores, valorizando também as contribuições do aluno. Para proceder esta análise, devemos reconhecer que a interpretação dos textos não deve ser limitada aos "direitos do professor", pois devemos abrir possibilidades para o lúdico e o subjetivo. Mesmo reconhecendo que os direitos dos leitores são limitados pelos direitos do texto, é necessária uma postura subjetiva e criativa para que o leitor possa construir novos sentidos para o texto a partir de sua experiência.

Dessa forma, utilizar e interpretar podem ser usados concomitantemente sem prejuízo para o leitor, que pode interpretar o texto sem contudo deixar de sonhar, sentir o texto próximo do seu universo para depois favorecer as abordagens interpretativas que figuram do espaço social. Talvez seja um dos motivos de o educando se afastar tanto da leitura literária, por não ter sua subjetividade, a sua vivência, relacionada com o que está sendo lido.

Aludimos, assim, a um ensino que potencialize o respeito à diferença cultural, que traga para escola não somente a canônica, mas também as culturas locais, populares e a cultura de massas, para torná-las objetos de estudo e crítica e proporcionar um diálogo aos textos/enunciados/discursos das diversas culturas locais com os textos da cultura valorizada, explorando a diversidade própria de sua comunidade escolar como o intuito de formar um cidadão flexível e protagonista de sua cultura.

É importante destacarmos que as contribuições dos estudos culturais são fundamentais para uma prática performática do cordel, pois expandiremos os textos selecionados para a diversidade da cultura popular. Nesse caso, pensamos que devemos valorizar a cultura popular como um bem coletivo e que precisa de espaço nas disciplinas escolares, já que "há uma luta contínua e necessariamente irregular e desigual, por parte da cultura dominante, no sentido de desorganizar e reorganizar constantemente a cultura popular" (HALL, 2003, p. 255). Portanto, os estudos culturais ultrapassam a fronteira da cultura hegemônica e "inclui belas artes, literatura e conhecimentos, as matérias regulares do currículo das ciências humanas, mas abrange também as artes negras, da mídia, os esportes e a cultura popular - costumava ser denominada de folclore e arte proletária" (KUPPER, 2002, p. 290).

Além disso, reforçamos a exploração da cultura popular como estratégia para aproximar o aluno dos textos produzidos em sua região. No caso desta pesquisa, a escolha do cordel se deu justa- 
mente por ser uma das principais narrativas populares do do nordeste brasileiro, registrando tanto fatos do cotidiano, como aspectos históricos desse povo. Outra justificativa para essa escolha do gênero é mostrar para os alunos que a literatura vai além dos textos canônicos, pois está presente na força estética dos cantares e contos populares. Tal reconhecimento nos convida a fazer relacionamentos entre a produção popular e os textos da cultura dominante, valorizando as particularidades desses produtos (HALL, 2003, p. 257).

A partir da polifonia, que se encontra atrelada ao conceito de cultura, os estudos culturais possibilitam a problematização e a compreensão do que é culturalmente humano, criando condições de novos diálogos entre os conceitos socioculturais que se propagam no contexto contemporâneo. Esse cenário implica em um descentramento da noção de cultura, porque esta nomenclatura abandona o centro das discussões, passando a permear, ou mesmo a visibilizar, as margens silenciadas que são representados pela cultura popular.

\section{Abordagens reflexivas sobre a concretização da leitura}

Nossa proposta pretende fomentar o prazer estético e a performance por meio do cordel, articulando com a formação crítica do leitor. Assim, planejamos promover vivências com literatura de cordel, por considerar a hipótese da formação do leitor na perspectiva estética, artística, cultural e social. Ou seja, mobilizar o olhar, o sentir para a ampliação do horizonte de expectativas de o leitor do ensino médio para apreciação, para degustação, na perspectiva de um desenvolvimento humano em seu sentido lato.

Nesse caminho, a literatura passa a ser vista como um fenômeno comunicativo, isto é, a teoria da recepção nos diz que o texto não é o único elemento do fenômeno literário, mas temos também a reação do leitor e, por extensão, precisamos explicar o texto a partir dessa reação, proveniente da interação do texto e o leitor. O leitor como protagonista nos faz pensar que a leitura é um ato subjetivo, já que o texto está repleto de elementos não ditos, que o leitor vai preenchendo, mas esses espaços não se oferecem à imaginação arbitrária.

Nosso desafio nas oficinas é aproximar o horizonte de expectativas do leitor das informações que o texto traz. Essa tarefa é possível por meio do diálogo e da reflexão coletiva. Reconhecemos que o texto prevê um leitor capaz de traduzir seus mecanismos estéticos e culturais, por mais simples que sejam. Tais movimentos passam pelo "leitor modelo" e pelo "leitor cooperativo", exigindo um leitor que identifique as opções do autor, que passam por uma "competência interpretativa" que pressupõe "como o texto se encarrega de construir através de suas pistas" (COLOMER, 2003, p. 96). Essa perspectiva pode limitar a leitura subjetiva, todavia ela pode ser considerada uma das possibilidades de leitura, deixando a criatividade do leitor aberta para o processo de colaboração interpretativa.

O processo de leitura subjetiva requer uma oficina que envolve seu aluno e o prepare para um movimento de entrar no texto, para traduzir as pistas dadas no texto para sentidos de sua realidade, de seu contexto cultural. Com essas vivências de literatura de cordel, a articulação entre os conhecimentos canônicos e os populares poderão fortalecer a formação do leitor crítico, porque toda "vivência artística" traz uma visão peculiar do mundo e preciamos "ouvir a experiência do outro não como menor, ou menos universal, mas como diferente" (ALVES, 2013b, p.36). 
Em nossas propostas práticas, precisamos aproximar a experiência da leitura do cordel das já vividas pelo aluno do ensino médio. Resgatar particularidades da estética lírica é fundamental para um oficina participativa, já que o prazer é visto como o mais alto valor do espírito, "pois é ao mesmo tempo alegria e signo: o signo de uma vitória de e sobre a vida, esta vitória que nos faz humanos" (ZUMTHOR, 2000, p.109).

Tal prazer da cultura popular também pode nos permitir vivenciar a literatura em sua dimensão socializadora, pois estamos explorando uma leitura compartilhada que "estabelece um caminho a partir da recepção individual até a recepção no sentido de uma comunidade cultural que a interpreta e avalia" (COLOMER, 2007, p.147). A intenção é criar espaços de leitura coletiva na escola de ensino médio, abrindo espaço para o diálogo entre as particularidades dos textos canônicos e do cordel.

Deixar um espaço para a valorização da cultura local é indispensável para uma prática de valorização do horizonte de expectativas dos participantes da oficina. Além disso, abrir espaço para a performance é reforçar a recepção subjetiva de cada um, visto que a literatura de cordel, "embora escrita, é na voz que encontra o seu grande instrumento de comunicação e recepção" (ALVES, 2013, p.40). Ao reverberar a leitura em voz alta, estamos nos projetando no texto oralizado. Em suma, o professor deve proporcionar um espaço de dramatização do texto lido, convencendo os alunos da importância de uma prática perfomática do texto.

Nessa proposta, o professor deve incentivar a performance do educando por meio da vocalização e encenação dos cordéis, ou seja, "transformar os alunos em atores, isto é, em parceiros da interação pedagógica parece-nos ser a tarefa em torno da qual se articulam e ganham sentido todos os saberes do professor" (TARDIF, 2002, p.221). Torna-se fundamental que os participantes tenham interesse pelo prazer do texto lido e ouvido. Na ritualização da linguagem, e, para o texto ser reconhecido por poético (literário) ou não, isso "depende do sentimento que nosso corpo tem. Necessidade para produzir seus efeitos; isto é, para nos dar prazer” (ZUMTHOR, 2000, p.35).

Assim, a recepção se produz em circunstância psíquica privilegiada: performance ou leitura. Parte-se da premissa de que o sujeito, ouvinte ou leitor, encontra a obra e a encontra de maneira pessoal. Essa consideração deixa íntegra a teoria da recepção, mas lhe acrescenta uma "dimensão que lhe modifica o alcance e o sentido. Ela aproxima, de algum modo, da ideia de catarse, proposta (em um contexto totalmente diferente) por Aristóteles" (ZUMTHOR, 2000, p.52).

Por essa concepção, propomos que a organização pedagógica das vivências leve em consideração a interação entre os processos intelectivos e a sensibilidade estética que a poesia suscita a fim de promover a apropriação do leitor. Como consequência, valorizamos a amplicação do horizonte de expectativas do leitor por meio da concretização do ato de ler: "O que produz a concretização de um texto dotado de uma carga poética são, indissoluvelmente ligadas aos efeitos semânticos, as transformações do próprio leitor, transformações percebidas em geral como emoção pura" (ZUMTHOR, 2000, p.52).

Entendemos que, por meio da emoção, fruição, o educando possa ampliar sua capacidade de reflexão e percepção abrindo seu horizonte de conhecimentos para o outro da cultura popular. Acreditamos que o cordel, além de reverberar a sensibilidade, pode também formar o leitor crítico, pois o texto poético comporta elementos informativo. Esse processo de leitura pede um leitor disposto a se envolver com a poesia e seus sentimentos como: "sensação-per- 
cepção-conhecimento-domínio do mundo" (ZUMTHOR, 2000, p.81). Nesse caso, o ouvir e o ver não servem apenas de órgãos de registro, são órgãos de conhecimento, e o sujeito é colocado no mundo para escutar, inferir, opinar, formar a sua criticidade. Essa ampliação de horizontes implica a formação do leitor.

\section{A performance poética nas oficinas}

Essa prática de leitura valoriza o ato de concretização do leitor, isto é, quando a performance lírica é experimentada por meio do processo de leitura subjetiva. Por esse motivo, nossas oficinas de vivências de literatura de cordel primam por uma prática de formação leitora, que valorize tanto os aspectos estéticos peculiares a essa literatura, como também relacione o mundo cantado com o universo social da escola. Didaticamente, seguiremos as orientações de José Helder Pinheiro Alves, que valoriza a leitura do texto lírico por suas peculiaridades:

\footnotetext{
Primeiro, pela extensão, que favorece uma leitura minimamente detida no espaço de uma ou duas aulas. Segundo, é possível o acesso a vários poemas de um mesmo poeta ou poetisa ou ainda a poemas de poetas que abordem um mesmo tema sem demandar um tempo maior como o da leitura de um romance. O tempo maior seria $\mathrm{o}$ da releitura e do debate compartilhado. Terceiro, por ter um investimento mais efetivo sobre a linguagem, ele permite, em certo nível, a percepção que os formalistas russos chamavam de literariedade (2015, p.156).
}

Assim, o gênero lírico também facilita a aproximação do aluno com o texto literário. A literariedade pode ser encontrada em vários cordéis, que exploram figuras de linguagem, ritmos e jogo de rimas que lhe dão um tom homorístico, que seduzem os leitores. A forma e o tema devem também incentivar o aluno a ler esses textos híbridos e populares. De sorte que a leitura do cordel em sala de aula pode desencadear outras curiosidades pelo texto lírico e a vontade de conhecer outros cordéis.

No início deste projeto, precisamos explorar alguns aspectos estéticos e formais do cordel como um texto lírico. Para isso, sugerimos a exploração da literariedade do cordel, porque os versos de cordel geralmente possuem versos de sete sílabas ou de seis, rimados e organizados em quadras com metáforas belíssimas, cujos poetas, considerados cânones, utilizam essa forma, a exemplo de Mário de Andrade.

Nosso segundo passo deu-se destaque ao anonimato da maioria dos autores de cordel e as particularidades desta arte que têm origem na cultura medieval e que chegou ao Brasil por meio da colonização portuguesa. Historicizar a importância do cordel como um das principais manifestações artísticas populares, e ampliar o interesse dos alunos para ouvir o que esses autores desconhecidos têm para nos dizer. Esses poetas aprimoram suas técnicas de compor ao vivo durante um longo trajeto profissional e "têm um interesse acentuado pelas palavras raras, utilizando esse conhecimento, por exemplo, nas pelejas e desafios" (ABREU, 2006, p.56).

Ao introduzir o debate em torno da especificidade do cordel e de sua história, partimos para a reflexão acerca dos valores da obra de arte. Essa postura crítica é muito importante para que possamos ampliar o horizonte de expectativa desses alunos que passam a aceitar as poéticas da voz com suas especificidades e beleza na camada sonora do texto. Com isso, deixamos claro que "não há obras boas e ruins em definitivo. O que há são escolhas - e o poder daqueles que as fazem. Literatura não é apenas uma questão de gosto: é uma questão política” (ABREU, 2006, p.112). 
Estabelecidas as negociações com os alunos, devemos considerar que a aprendizagem escolar deve transcender ao conhecimento puramente científico, pois deve haver o encontro entre a emoção e a intelecção. Assim, propomos que o primeiro contato do grupo com o objeto literário seja a partir da fruição de modo a suscitar a sensibilização. Esse jogo com as possibilidades de leitura é parte desta prática voltada para a descoberta dos sons do cordel.

Nesse movimento de suscitar a sensibilidade dos sujeitos, escolhemos o cordel "As proezas de João Grilo", de João Martins de Athayde. As histórias de João Grilo povoaram a imaginação de muitas crianças nordestinas. Várias cordelistas contaram uma versão desse personagem de espírito moleque, que estava sempre disposto a pregar uma peça nos poderosos e injustos. Esta versão que vivenciamos relata as travessuras do personagem no encontro com o vigário. Seguem algumas estrofes:

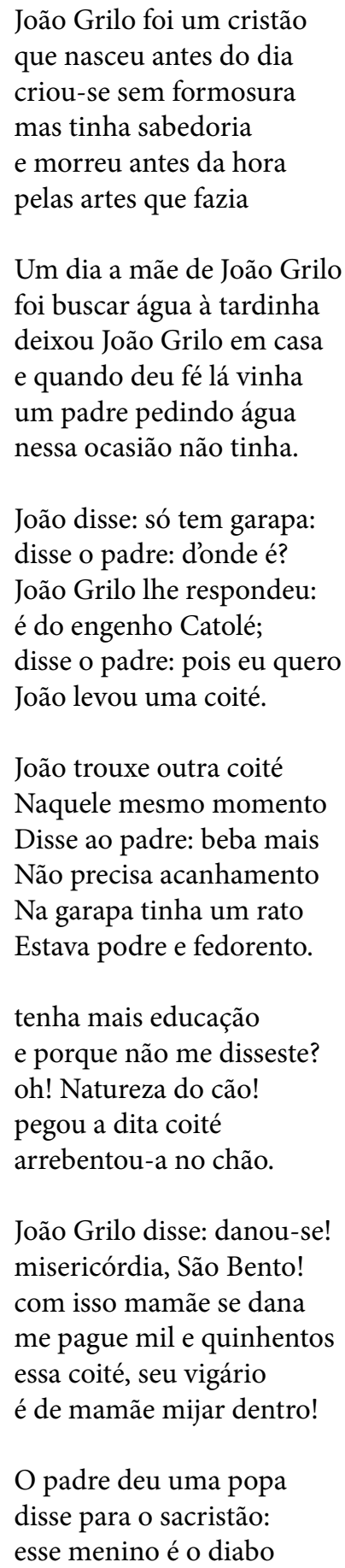




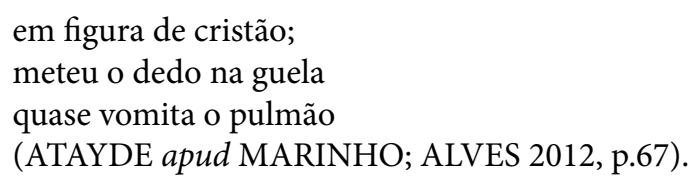

A primeira leitura em voz alta pode ser feita pelo professor ou por um aluno preparado com antecedência para participar desta prática. Normalmente, esse tipo de leitura em voz alta provoca um estado de concentração dos ouvintes, que ficaram atentos e interessados em não perder o fio condutor da história. Esse exercício de ouvir é parte da cultura oral: "O texto recebido pelo ouvido gera a consciência comum, do mesmo modo como a linguagem cria a sociedade que a fala” (ZUMTHOR, 1993, p.155). Exerce-se aí a função social da obra poética que está ligada à ação da voz.

Concluída a leitura, iniciou-se o debate para a identificação dos intertextos daquele cordel. Por fazer parte do imaginário audiovisual, os alunos afirmavam que se tratava do mesmo personagem do filme o Auto da Compadecida, de Ariano Suassuna e ficaram encantados em saber que a obra baseava-se em três cordéis distintos. Tais esclarecimentos e discussões sobre o processo de construção do cordel são salutares. Esse envolvimento incial reforça a premissa da importância de se levar em conta o horizonte de expectativa dos alunos e por prática pedagógica que saiam do cotidiano das aulas tradicionais.

A referência a outros textos lidos não aparece de forma instantânea, por isso devemos manter essa prática de resgate de obras já conhecidas pelos alunos. Assim, os alunos se aventuraram em intervenções, visto que o texto lido em classe aparece mais durante trocas e comentários em grupo. Nesse movimento da leitura, valorizamos também as competências lexicais e de vocabulário do leitor, assim, no processo de leitura inicial, não devemos evitar seus erros, pois são necessários para o seu aprendizado (ROUXEL, 2013b). Nesse momento da oficina, identificamos alguns processos estéticos do texto e passamos a comentar a metalinguagem desse gênero, deixando que eles identificassem: personagem, metáfora, trama, termos regionais, significado de outras palavras.

O debate e reflexão deve avançar até o envolvimento dos educandos com o texto, e como alguns alunos citaram o nome do autor. Ao fazerem referência ao universo do cordel, podemos identificar a ligação deles com a comunidade interpretativa do cordel. Esse reconhecimento é possível porque nossas leituras surgem da família que fomos criados, do nosso local de trabalho, das instituições a que pertencemos, e de outras práticas. Poderíamos, então entendê-las como parte de "comunidades interpretativas" (2003, p.362). O fato de os alunos perceber que o universo do imaginário do cordel é parte da comunidade interpretativa deles foi decisivo para a continuidade de nossos trabalhos. Por isso, resolvemos falar sobre a recente morte do escritor paraibano Ariano Suassuna por meio do cordel "A chegada de Ariano Suassuna no céu", de Klevisson Viana e Mestre Bule-Bule, que relatam um plano de Jesus em enviar a morte para buscar Ariano Suassuna a fim de fazer uma peça teatral no céu. Abaixo trazemos um fragmento para contextualizarem esta experiência de vivência leitora:

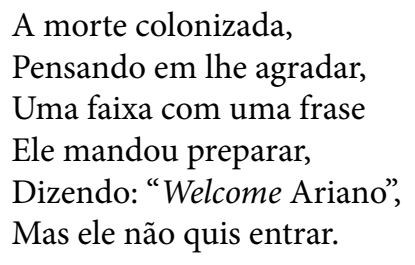




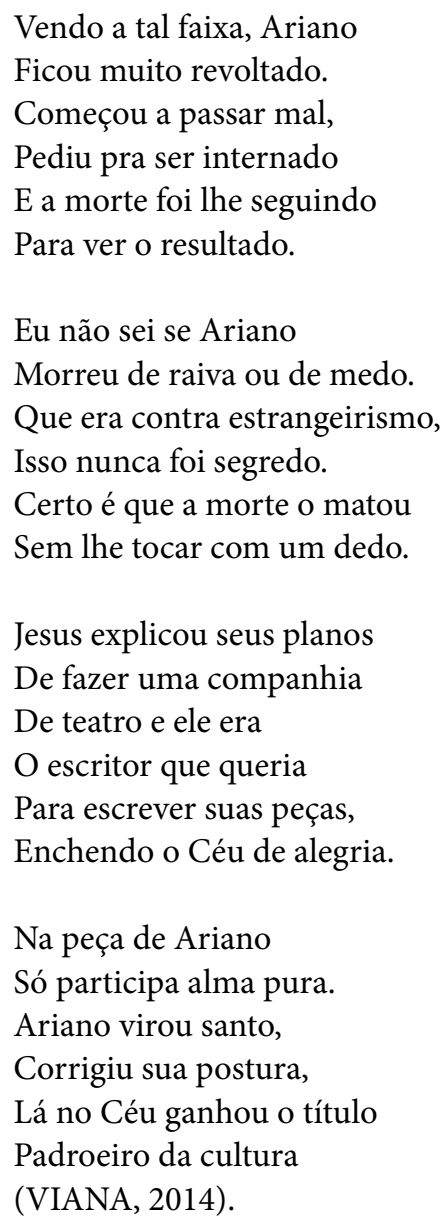

A leitura desse segundo texto trouxe uma perspectiva mais emotiva para a oficina. As questões do ouvir e do observar atento estavam atreladas à emoção. Percebíamos isso na fisionomia dos alunos e na fala de uma aluna: "É tão difícil falar sobre a morte, mas dessa forma foi tão comovente e envolvente, que eu não sabia se ria ou não com a morte do autor do Auto da compadecida" (participante A).

Essa experiência vivida pelos ouvintes reforça nossa proposta de lermos mais textos em nossas aulas, explorando a forma lírica. Consideramos que as vivências com o cordel pode promover o processo dialético com a catarse, pois há descarga das tensões, das emoções angustiantes para a transformação de sentimentos. Como havíamos planejado, a escolha de um texto que trazia um diálogo com o anterior, motivou a audição do grupo. De forma que o cordel lido cumpriu sua função, provocando uma reação estética por meio da emoção sem deixar de lado a cultura popular coletiva, visto que a leitura é também uma prática "compartilhada; possui uma expressão institucional; relaciona-se com o fato de que você é parte de uma instituição" (HALL, 2003, p.357). Esse elo que o leitor pode manter com sua comunidade é fundamental para a recepção do texto lido.

Interessante notar como o prazer pela leitura deve ser precedido pela leitura em voz alta, pois os educandos participaram ativamente do cordel lido, fazendo inferências lógicas e muitos não sabiam que o autor do Auto da Compadecida já havia falecido. Assim, a primeira parte da proposta é tornar o cordel desejável, suscitar a emoção e curiosidade, que deve levar em conta uma pedagogia mais sensível, deixando claro que não queremos romantizar o ato pedagógico, mas buscar formas de sensibilizar o educando. 
Essa experiência da primeira parte de nossa oficina foi muito importante para reverter os preconceitos contra o gênero cordel e contra as aulas de leituras performáticas. Se no início de nossa pesquisa os alunos ficaram em dúvida quanto à utilização do cordel em sala, como afirma um participante "O cordel é legal, mas não é uma leitura pra se fazer na escola, não tem nada a ver com os assuntos daqui. Se for usar corre o risco de virar uma bagunça na sala" (participante B). No final dessa oficina, houve o reconhecimento da beleza sonora e da riqueza cultural desse gênero lírico.

\title{
A performance em foco
}

A segunda parte desta proposta versa sobre a leitura em voz alta de forma a elucidar a performance por entender que "a ausência de espaço na escola para a arte de contar e a arte de ouvir é responsável direta pelo desinteresse da criança e do adolescente pela leitura" (MARTINS, 2012, p.148). O ouvinte, quando "interpelado", intervém, tornando-se um dos componentes fundamentais da poesia vocal. No momento em que fazemos a leitura em voz alta, alguém escuta, deixando-se captar pela voz do outro e efetivando a função social da voz.

Assim, propomos que o educador faça a primeira leitura em voz alta, como exemplo, escolhemos o cordel "Maria Bonita: a musa de Lampião", de Antônio Barreto, que faz um relato bem humorado da vida de Maria Bonita; vale ressaltar que até os dias de hoje é uma das personagens mais conhecidas e comentadas no nordeste.

\author{
Maria se destacava \\ Distribuia dinheiro \\ E a muitos ajudava \\ Sobretudo o povo pobre \\ Que dela necessitava. \\ Ao lado de Lampião \\ 8 anos de aventura \\ Uma mescla de amor \\ De mistério e de bravura: \\ A Bahia e Pernambuco \\ Na mais bela partitura. \\ Mas não somos tão eternos, \\ Tudo tem começo e fim \\ Um dia nos despedimos \\ Nas asas de um querubim \\ Pois então Maria Bonita \\ Foi morar noutro jardim.. \\ Na grota de Angico enfim \\ Deu-se a batalha final \\ Em vinte e oito de julho (1938) \\ Não mais o bem e o mal \\ Pois Maria e Lampião \\ Seguiram no mundo astral (BARRETO, 2010).
}

Os alunos pareciam bem atentos à leitura, alguns se colocaram que já ouviram falar da personagem. É importante ouvir os alunos, conversar sobre seus posicionamentos perante o texto. Logo, a criação de uma empatia é imprescindível na intervenção. "Uma arte, tomando forma 
e vida social por meio da voz humana, só tem eficácia caso se estabeleça uma relação bastante estreita entre: intérprete e auditório: aí está um dado fundamental, que se prende às estruturas da linguagem humana" (ZUMTHOR, 1993, p.227-228).

Depois da leitura do professor, é hora de solicitar que o educando também leia em voz alta o cordel. Sugerimos, antes de tudo, um movimento de identificação: buscamos os temas mais próximos, o que mais nos agrada. Nesse viés, sugerimos levar para a sala de aula vários cordéis de autores diversos, de modo a colocar à disposição dos educando para as devidas escolhas e posterior leitura em voz alta. Essa abordagem preocupa-se com o íntimo dos alunos, pois é “[...] a partir das leituras subjetivas que se pode negociar significados compartilhados" (ROUXEL, 2013a, p.162).

No início, é natural que eles fiquem receosos em decidir, já que geralmente é o professor quem escolhe os textos que o aluno lerá na sala de aula. As preferências foram diversas: uma aluna optou por "Água: fonte da vida", segundo a aluna, ela se lembrou da escassez da água; outra preferiu o cordel "ABC do HIV", justificou que tem um conhecido que tem essa doença; outra preferiu o cordel "Nas ondas da internet", porque, segundo a mesma, "todo mundo agora tem que está conectado". Outros optaram pela temática etnicorracial: "Zumbi”, "Casa grande e senzala", "Castro Alves", de Antônio Barreto.

Os alunos ficaram mais animados para ler por ser um cordel da sua escolha e, assim, leram ao mesmo tempo em que riam, cada um, gradativamente, aumentou o tom da voz à medida que percebia que a turma acompanhava. A leitura em voz alta foi basilar para chamar a atenção dos demais participantes.

É importante observar que à proporção que o sujeito fica mais solto, ele começa a gesticular, a se apropriar da voz com mais firmeza. A espontaneidade expressiva é tão marcante que se percebe claramente a ligação entre gesto e palavra, denominada de "verbo-motor" dentro de uma perspectiva performancial (ZUMTHOR, 2005, p.147). A presença forte do "verbo-motor" na performance é tão marcante que a apropriação do texto estabelece-se claramente já na leitura em voz alta. Quanto a isso, uma aluna se posiciona: "o cordel é como ouvir uma música para nossos ouvidos. É uma sensação muito boa. A leitura em voz alta faz com que as pessoas entendam melhor e ajuda a enriquecer a escrita e a fala, nos tornando mais cultos" (participante C).

À medida que os educandos leem, percebem as rimas, o ritmo e passam a incorporar o espírito lúdico desta proposta, visto que "a ordenação rítmica ou simétrica da linguagem, a acentuação eficaz pela rima ou pela assonância, o disfarce deliberado do sentido, a construção sutil das frases, tudo isto poderia consistir-se em outras tantas manifestações do espírito lúdico" (HUIZINGA, 2000, p.97).

Quando o educador perceber o envolvimento do aluno com o cordel, ele passa à parte prática de identificação da parte estrutural do cordel. É preciso esclarecer que um bom cordel necessita de boas rimas. Quanto ao uso das sextilhas, o segundo, o quarto e o sexto versos deverão rimar; no caso das septilhas, a rima será com o segundo, quarto e sétimo versos. Quanto à oração, também é importante dizer que é aquilo que os eruditos denominam de coerência e coesão, que não pode ser qualquer rima, é preciso haver um encadeamento lógico da frase, de forma harmoniosa. O entendimento das especificidades do cordel fica bem mais fácil quando o educando vivencia a fruição do cordel, primeiro. Claro que nas vivências seguintes sempre é bom retomar de forma contextualizada. 
Temos a certeza de que proporcionar experiências estéticas com o cordel por meio da socialização da literatura ampliou a construção da atividade leitora e enriqueceu os universos culturais dos alunos. Essa perspectiva em relação à escola conduz a propor as vivências de literatura de cordel, primeiro porque foi demonstrado nos questionários que todos tinham conhecimento sobre o objeto literário, embora alguns considerassem que não era uma leitura pertinente na escola.

\section{Considerações finais}

A prática performática de leitura do cordel vai além do livro didático e da história da literatura própria do ensino médio. Nossa proposta valoriza o compartilhamento das informações entre os participantes e, quando possível, entre os familiares. Essa troca de experiências de leituras envolve o leitor em formação, pois saber que o lido em classe é conhecido dos seus pais criam-se laços entre a escola e as famílias. Isso corresponde à ideia de que se melhora a autoimagem do educando "sobre sua cultura de origem e permite aos pais, que frequentemente não dominam o idioma oficial escrito, participarem no processo de aprendizagem de seus filhos" (COLOMER, 2007, 150).

Assim, sugerirmos que o primeiro contato seja apenas com a intenção de criar "o gosto" por essa literatura, e alguns relataram o quanto é bom ouvi-la, pois o ritmo, as rimas se assemelham a uma música. Na segunda etapa da vivência, fizemos a leitura em voz alta e convidamos os alunos a participaram. Uma das alunas registrou no seu depoimento escrito: "O cordel nos ajudou muito a entender os assuntos que lemos, ajudou também a nos comunicar com as pessoas. Quando lemos em voz alta vamos tirando a vergonha e o medo de se soltar" (participante C). Nesse sentido, a experiência com a voz marcou o processo de aprendizagem desses, já que a performance é presente, que Zumthor denomina como um "ato pelo qual um discurso poético é comunicado por meio da voz e, portanto, percebido pelo ouvido" (2005, p.87).

Buscamos indícios de transformações, sinalizados nos depoimentos dos educandos na última vivência, e percebemos que a leitura em voz alta do cordel possibilitou senti-lo, deixar-se afetar e ter a capacidade de criar significações. As diferentes funções sociais da voz, em sua grandiosidade poética trouxe bons resultados para o envolvimento do participantes que passaram a ouvir melhor com mais atenção os textos: "O efeito vocal dá uma impressão de presença que se impõe, preenchendo um espaço tão material quanto semântico, em detrimento das impressões de fugacidade de renovação, de duração, que demarcam nossa percepção no tempo" (ZUMTHOR, 2005, 82). Entendemos a voz que emana da presença de quem está lendo ser tão intensa de forma a atingir os sentidos de quem ouve a ponto de o efeito temporal ser atenuado.

Diante dos bons resultados, a impressão que tivemos com as vivências foi justamente perceber como o ouvir foi capaz de interpelar o educando pois, quando alguém pára para ouvir a poesia, começa-se a gerar um significado, algo é suscitado. Não só os alunos que ouvem são interpelados, mas quem está lendo também é afetado pela sua própria voz. Zumthor (2005, p.92) ilustra que, quando um pastor canta, sozinho, nos países de montanhas altas, não tem nenhum ouvinte a seu lado. No entanto, na verdade, ele tem um ouvinte: a própria montanha, cuja beleza o canto exalta.

A transmissão do cordel na nossa vivência supunha a presença física simultânea do que lia e a do que escutava, o que implicava uma imediaticidade, uma troca muito rápida: olhares, gestos. $\mathrm{O}$ que nos faz pensar que, se fosse apenas a leitura silenciosa do poema, a leitura se tornaria muda e solitária, por uma ruptura em relação ao corpo, e a presença do aqui e agora, ou seja, a presença 
espaço-temporal, é elemento que também auxilia a recepção. Esse processo de leitura faz parte das estratégias de ampliação do horizonte de expectativa do nosso alunos, que passam a valorizar a cultura oral como parte das manifestações artísticas, que podem ser lidas com seus mais variados sentidos, já que no "processo contínuo de significação do mundo cultural e ideológico, que está sempre significando e ressignificando - esse processo é sem fim” (HALL, 2003, p.362).

Dessa forma, sem nenhuma pretensão de impor um método como detentor de verdades ou determinar uma didática, esta proposta permite traçar alguns indicadores de que a vivência com literatura de cordel pode transformar a ação docente. Nossa pesquisa tem indicado que o trabalho com o cordel, por meio da leitura em voz alta e da performance, pode permitir a reação estética, que por sua vez causa o estranhamento. Por essa linha de pensamento, acreditamos que seja possível formar leitores críticos na escola, é acreditar que a socialização, o compartilhamento da literatura podem ser início da ampliação de expectativas do leitor.

\section{Referências}

ABREU, Márcia. Cultura Letrada: Literatura e leitura. São Paulo: Editora UNESP, 2006.

ALVES, José Hélder Pinheiro. “O que ler? Por quê?” A literatura e seu ensino. In: DALVI, Maria Amélia; RESENDE, Neide Luzia de; Jover-Faleiros, Rita (Orgs). Leitura de literatura na escola. São Paulo: Parábola, 2013. p.35-50.

ALVES, José Helder Pinheiro. "Contribuição da estilística para o ensino da poesia”. Via Atlântica, São Paulo, n. 28, p.143-159, 2015.

BARRETO, Antônio. Maria Bonita: a musa de Lampião. Salvador. Ba: Edições Akadicadikum. 2010.

COLOMER, Teresa. Andar entre livros: a leitura literária na escola. Trad. Laura Sandroni. São Paulo: Global. 2007.

COLOMER, Teresa. A formação do leitor literário. Trad. Laura Sandroni. São Paulo: Global. 2003.

COSSON, Rildo. Letramento literário: teoria e prática. São Paulo, SP: Contexto, 2009.

HALL, Stuart. Da diáspora: identidades e mediações culturais. Trad. Adelaine La Guardiã Resende. (et al.). Belo Horizonte: Ed. UFMG, 2003.

HUIZINGA, Johan. Homo Ludens. Tradução: João Paulo Monteiro. São Paulo: Editora Perspectiva, 2000.

KUPER, Adam. “Cultura, diferença e identidade”. In: Cultura: a visão dos antropólogos. Tradução Mirtes Frange de Oliveira Pinheiros. São Paulo: EDUSC, 2002.

MARINHO, Ana Cristina; ALVES, José Helder Pinheiro. O cordel no cotidiano escolar. São Paulo: Cortez, 2012.

MARTINS, Ricardo André Ferreira. "Oralidade, literatura e leitura em voz alta: uma abordagem possível para a formação de leitores”. Nonada - Letras em Revista. Porto Alegre, n.18, p.142-154, 2012.

ROUXEL, Annie. “Tensão entre utilizar e interpretar”. In: ROUXEL, Annie; LANGLADE, Gérard; RESENDE, Neide Luzia (org). Leitura subjetiva e ensino de literatura. Vários tradutores. São Paulo: Alameda, 2013. 
ROUXEL, Annie. “Aspectos metodológicos do ensino da literatura”. In: DALVI, Maria Amélia; RESENDE, Neide Luzia de (orgs). Leitura de literatura na escola. São Paulo: Parábola, 2013b.

TARDIF. Maurice. Saberes docentes e formação profissional. Petrópolis, RJ: Vozes, 2002.

VIANA, klevisson; BULE-BULE, Mestre. A chegada de Ariano Suassuna no céu. FortalezaCe: Tupynanquim Editora. 2014.

ZUMTHOR, Paul. Escritura e Nomadismo: entrevistas e ensaios. Tradução: Jerusa Pires Ferreira, Sonia Queiroz. Cotia: Ateliê Editorial, 2005.

ZUMTHOR, Paul. A letra e a voz. São Paulo: Companhia das Letras, 1993.

ZUMTHOR, Paul. Performance, Recepção, leitura. Tradução de Jerusa Pires Ferreira e Suely Fenerich. São Paulo: EDUC, 2000. 